\title{
Cellulose Nanocrystal from Washingtonia Fibre and Its Characterization
}

\section{Mohammad Jawaid ${ }^{1}$, Lau Kia Kian ${ }^{1}$, Hassan Fouad ${ }^{2}$, Ramzi Khiari ${ }^{3,4,5, *}$, Othman Y. Alothman ${ }^{6}$ and Mohamed Hashem ${ }^{7}$}

\author{
${ }^{1}$ Laboratory of Biocomposite Technology, Institute of Tropical Forestry and Forest Products (INTROP), Universiti Putra Malaysia, \\ Selangor, Malaysia \\ ${ }^{2}$ Applied Medical Science Department, Community College, King Saud University, Riyadh, Saudi Arabia \\ ${ }^{3}$ CNRS, University of Grenoble Alpes, Grenoble, France \\ ${ }^{4}$ Department of Textile, Higher Institute of Technological Studies of Ksar Hellal, Ksar Hellal, Tunisia \\ ${ }^{5}$ University of Monastir, Laboratory of Environmental Chemistry and Cleaner Process (LCE2P-LR21ES04), Monastir, Tunisia \\ ${ }^{6}$ Chemical Engineering Department, College of Engineering, King Saud University, Riyadh, Saudi Arabia \\ ${ }^{7}$ Dental Health Department, College of Applied Medical Sciences, King Saud University, Riyadh, Saudi Arabia \\ *Corresponding Author: Ramzi Khiari. Email: khiari_ramzi2000@yahoo.fr
}

Received: 23 July 2021 Accepted: 17 August 2021

\begin{abstract}
Cellulose nanocrystal (CNC) is a biomaterial derived from plant lignocellulosic components, widely applied in various industrial fields. Concurrently, with the growth of awareness in developing green nanomaterial, the explored Washingtonia fibre could be alternative biomass for obtaining CNC products. In the present work, different acid concentrations of $5 \%, 15 \%$, and $25 \%$ hydrochloric solutions were employed to produce CNCs from Washingtonia fibre. With the chemical treatments, the yield of the CNC product was successfully retained at $21.6 \%-25.1 \%$. Individually separated and needle-shaped CNC particles could be observed under the microscopic viewing with the increased acid concentrations. From elemental analysis, a relatively pure cellulose compartment was produced for all CNC samples. The zeta potential values between -10 to $-16 \mathrm{mV}$ proved that each nanoparticle sample possessed dispersion ability within an aqueous solution. Meanwhile, the degree of crystallinity and the thermal behavior of CNCs were enhanced with the increased acidic concentrations. Hence, the isolated CNCs (with 15\%) from Washingtonia fibre lead a CNC with the highest aspect ratio (30). This parameter is so important that these structures show empowering points of view as nanomaterials for reinforced polymer composites, and it could be a reliable nano-filler for the composite fabrication process in the future.
\end{abstract}

\section{KEYWORDS}

Cellulose nanocrystal; washingtonia fibre; structure; degree of crystallinity; thermal behavior

\section{Introduction}

The advancement of novel bio-based materials from residues biomass has become the center of researchers and analysts to moderate climate change. Agro-wastes are a copiously accessible and reasonable cheap source of cellulose [1,2]. The valorization of this lignocellulosic material is respected as an energetic way that contributes to the foundation of an economical and cleaner environment [3-6]. 
Washingtonia palm tree is a plant that is commonly cultivated for landscaping purposes, and its harvested fruit can be used for food manufacturing. It is found across the Middle East, Southern United States, Southern Europe, and North Africa [7,8]. Nevertheless, huge agro-waste can be shaped from the Washingtonia plant due to unsuitable management. The trunk section of the Washingtonia plant is normally made up of plenty amount lignocellulosic contents where the cellulose serves as the main component. This gives it with large potential for producing cellulose derivative products and/or to produce a high value-added product such as microcrystalline cellulose (MCC), cellulose nanocrystal (CNC) [9-14].

Cellulose nanocrystal (CNC) is a needle-like cellulose crystallite produced via the hydrolysis of acid treatment. Commonly, it keeps a diameter of between 5 and $30 \mathrm{~nm}$. While the length is between 100 and $600 \mathrm{~nm}$, as well as fascinating physical properties like stable thermal behavior, excellent reinforcing capability, and biocompatibility [15-18]. These have made it broadly appropriate in paper generation and acting nanocharges and/or nanoparticles in nanocomposite materials [19,20]. Su et al. [14] prepared CNC from MCC using $64 \mathrm{wt} \%$ sulfuric acid under vigorous agitation. Xing et al. [21] obtained CNC by hydrolyzing Tetra Pak paperboards with $64 \mathrm{wt} \%$ sulfuric acids. Also, another study by Benini et al. [22] had used the Taguchi method with various $50-64 \mathrm{wt} \% \mathrm{H}_{2} \mathrm{SO}_{4}$ concentrations for gaining nanocellulose from Imperata Brasiliensis grass. Teodoro et al. [23] employed the conventional method of $60 \mathrm{wt} \%$ $\mathrm{H}_{2} \mathrm{SO}_{4}$ to produce CNW from cotton. Khattab et al. [12] utilized $65 \mathrm{wt} \% \mathrm{H}_{2} \mathrm{SO}_{4}$ to extract $\mathrm{CNW}$ from rice straw. However, the partially immiscible between $\mathrm{H}_{2} \mathrm{SO}_{4}$ and water molecules could cause phase separation and inconsistent cellulose degradation during nanoparticle isolation. More recently, Seta et al. [24] had used $75 \mathrm{wt} \%$ maleic acid to gain CNC from bamboo pulp fibre, while Baek et al. [25] had employed $75 \mathrm{wt} \%$ phosphoric acids to obtain CNC from hardwood kraft pulp. The application of these extremely high concentrated organic acids was considerably environmental unfriendly.

A low concentrated $\mathrm{HCl}$ hydrolysis method was adopted to meet the environmental protection purpose, in the present work for $\mathrm{CNC}$ isolation. Also, since hydrochloric acid $(\mathrm{HCl})$ is highly miscible with water, it could form a homogeneous acidic solution in low concentration. Meanwhile, there is no work reported on Washingtonia fibre, which acting as raw biomass material for isolating CNC particles. Therefore, characterization was conducted for the obtained CNCs to examine their morphology particle size, elemental composition, dispersion behavior, and production yield. Additionally, the determination of the degree of crystallinity, the thermal behavior and the FTIR footprint were also established to study the extracted nanoparticles product widely.

\section{Materials and Methods}

\subsection{Materials and Chemical Products}

Washingtonia trunk fibre was harvest from Saudi Arabia (Riyadh). The fibre was pounded into little pieces, approximately little than $1 \mathrm{~cm}$, and dried in an oven for one day. Several chemical products were used as received from the suppliers without further purification, namely $\mathrm{NaOH}$ (sodium hydroxide, CAS: 1310-73-2), $\mathrm{C}_{2} \mathrm{H}_{4} \mathrm{O}_{2}$ (acetic acid, CAS: 6419 7), $\mathrm{NaClO}_{2}$ (sodium chlorite, CAS: 7758-19-2), $\mathrm{HCl}$ (hydrochloric acid 37\%, CAS: 7647-01-0).

\subsection{CNC Preparation}

The grounded fibre was firstly cooked with $500 \mathrm{ml}$ of $5 \% \mathrm{NaOH}$ for $5 \mathrm{~h}$ at $80^{\circ} \mathrm{C}$ with the aim of swelling the cellulosic components and removing lignin which might help in the depolymerization process. Then the solid alkali fibre filtrate was obtained after filtration through nylon membrane $(1 \mu \mathrm{m})$ with distilled water. After that, the fibre was treated with $500 \mathrm{ml}$ of $2 \% \mathrm{NaClO}_{2}$ (acidified with $5 \mathrm{~mL} \mathrm{C}_{2} \mathrm{H}_{4} \mathrm{O}_{2}$ ) for $2 \mathrm{~h}$ at $80{ }^{\circ} \mathrm{C}$ with constant stirring. Herein, the filtrate of residual lignin and hemicellulose was eliminated through filtration, and the collected $\mathrm{NaClO}_{2}$-treated fibre residue was washed with distilled water until 
showing the white color. Further, acid hydrolysis was conducted with different $\mathrm{HCl}$ concentrations $(5 \%$, $15 \%$, and $25 \%$ ) for $30 \mathrm{~min}$ at $80^{\circ} \mathrm{C}$ to disintegrate the fibre into $\mathrm{CNC}$ nanoparticles. The ensuing solution was then quenched for its acidic reaction treatment several times using cold distilled water and subsequently neutralized to around $\mathrm{pH} 3$ through centrifugation. Afterwards, the white colloidal suspension was kept for $1 \mathrm{~h}$ to favor the sediment of the residual micro-sized cellulose. In contrast, the supernatant portion containing pure CNCs was collected for the dialysis process. Dialysis was carried out for 7 days in order to remove the excessive ionic elements of natrium $\left(\mathrm{Na}^{+}\right)$, chloride $\left(\mathrm{Cl}^{-}\right)$, chlorite $\left(\mathrm{ClO}_{2}^{-}\right)$, and acetate $\left(\mathrm{CH}_{3} \mathrm{COO}^{-}\right)$, which were generated during chemical treatments. Lastly, the suspension was freeze-dried to obtain $\mathrm{CNCs}$ solid product. The $\mathrm{CNC}$ samples isolated with different $\mathrm{HCl}$ concentrations of $5 \%, 15 \%$, and $25 \%$ were designated as $\mathrm{WNCC} 1, \mathrm{WNCC} 2$, and $\mathrm{WNCC} 3$, respectively.

\subsection{CNC Characterization}

\subsubsection{The Morphology and the Chemical Characterization}

Transmission Electron Microscope (TEM) was applied through FEI Tecnai F20 to examine the nanostructure of CNC nanoparticles. The tests were weakened to the concentration of $10^{-4} \mathrm{wt} \%$. Then, $0.6 \mu \mathrm{L}$ of cellulose nanocrystals suspensions was dribbled onto a 300-mesh carbon-coated formvar copper framework, employing a labnet micropipette, and the water was permitted to vanish. The extra drop of each prepared CNCs suspension was added to their respective grids to raise the number of cellulose particles, and the process was repeated. The particle size was measured for the nanoparticles via the Image $\mathrm{J}$ software method. It consists of determining the dimensions of each prepared $\mathrm{CNC}$ which were evaluated by digital image analysis (ImageJ) of TEM micrographs using a minimum of $110 \mathrm{CNC}$. The average diameter and length were measured for each kind of quality.

Elemental composition for each $\mathrm{CNC}$ sample was also analyzed and observed through Energy Dispersive X-ray (EDX) analysis. Meanwhile, the dispersion behavior was studied with zeta potentials by Dynamic Light Scattering (DLS) using the equipment of Malvern Zeta sizer Nano ZS. Additionally, the yield (\%) of CNCs production was calculated with the Eq. (1) provided as below:

Yield $(\%)=\frac{\left(M_{2}-M_{3}\right)}{M_{1}} \times 100$

where $\mathrm{M}_{1}$ is the raw Washingtonia fibres weight; $\mathrm{M}_{2}$ is the total weight of CNCs in weighing container; $\mathrm{M}_{3}$ is the weighing container.

\subsubsection{Functional Chemistry Analysis}

The functional chemistry of CNC samples was studied with Thermo Nicolet Nexus 670. The samples were pelletized after grinding with $\mathrm{KBr}$ before analysis. The obtained FTIR spectra were established by measuring the absorbance of a sample between 4000 and $500 \mathrm{~cm}^{-1}$ wavenumbers. The sample was analyzed at 32 scans with $4 \mathrm{~cm}^{-1}$ resolution.

\subsubsection{Degree of Crystallinity}

The degree of crystallinity was calculated according to Segal al. method [26] and as given in Eq. (2).

Crystalline degree, $\operatorname{Crd}(\%)=\frac{I_{m p}-I_{a m}}{I_{m p}} \times 100$

where, $\mathrm{I}_{\mathrm{mp}}$ corresponds to the maximum intensity at around $2 \theta=22.5^{\circ}$, and $\mathrm{I}_{\mathrm{am}}$ corresponds to the minimum intensity at around $2 \theta=19.1^{\circ}$. 
The test was established by employed A PANalytical Empyrean X-ray diffractometer (XRD) as an instrument device. The X-ray generator was working at $40 \mathrm{~mA}$ and, $45 \mathrm{kV}$ with a slow scan rate of $2^{\circ} \cdot \min ^{-1}$, and the tests were kept on a nickel-coated steel holder.

\subsubsection{Thermal Stability Analysis}

The thermogravimetry (TGA) and Derivative thermogram (DTG) of prepared CNCs were determined to study the thermal behavior stability and compare their efficiency. The test was established by using a TA-SDT Q600 thermogravimetric analyzer. It led to heating the sample between 30 and $900^{\circ} \mathrm{C}$ and at $10{ }^{\circ} \mathrm{C} \cdot \mathrm{min}^{-1}$ as a heating rate under nitrogen purge atmosphere. The Differential Scanning Calorimetry (DSC) was also determinate by heating the sample at a $10^{\circ} \mathrm{C} \cdot \mathrm{min}^{-1}$ heating rate between $30-600^{\circ} \mathrm{C}$. The experimental tests were done at least in duplicate.

\section{Results and Discussion}

\subsection{Characterization of CNCs from Washingtonia Fibre}

From TEM examination, WNCC1 presented its aggregated nanostructure, resulting in the partial disintegration of fibre fibrils [27]. With increased acidic concentration, both WNCC2 and WNCC3 samples showed needle-like nanocrystallites feature [12]. This resulted from the presence of adequate hydronium ions that had facilitated the degradation of amorphous cellulose parts and ultimately released small nanocrystals $[13,25]$. From SEM images, it cannot be seen the macro-particles. It can be confirmed that no big fragment can be observed and/or micro fibrillated cellulose (MFC and/or CNF). This proves the success of the preparation of CNCs again. In addition, from TEM viewing, the dented and protruding surface of WNCC1 was contributed by its unsymmetrical arrangement of fibrous bundle features [22]. The surface became finer for WNCC2 owing to the cellulose crystallite separation by the stronger acidic condition [28]. Additionally, WNCC3 showed a relatively smooth and well-organized nanostructure contributed by the uniform acid hydrolysis degradation process [23]. Apart from that, the measured average width size was gradually decreased from WNCC1 to WNCC2, indicating singular nanocrystals were isolated from a bunch of fibres [21]. However, the average length size for WNCC1 was shorter than WNCC2.

This was probably inconsistent hydrolysis reaction of dilute acid could influence nanoparticle formation and subsequently reduced overall sizes of WNCC1 [29,30]. With increased acid concentration, a further decrement of width and length was obtained for the WNCC3 product, providing it great suitability for composite material processing. Hence, the aspect ratio of WNCC1, WNCC2 and WNCC3 was about 22, 30 and 23, respectively. These obtained values seem to be as aspect is very lower than when it was compared to marine biomass "posidonia oceanica" leaves and balls CNC's (75 and 35) [31,32] and comparable and better than others raw materials such cotton, ramie, wood, etc. [9]. In addition, it can be concluded that the condition leading to the preparation of WNCC2 (obtained with $15 \%$ of $\mathrm{HCl}$ ) is the best because it is given the highest one as aspect ratio. This factor is important. Since it can be given an idea about the mechanical properties of obtained films, taking as an example the equation determined by Bras et al. [33] $\left(y=0.0027 x^{2}-0.0022 x+0.7581\right.$; where $X$ is representing the aspect ratio and $Y$ is the Young modulus), it can be estimated that the highest modulus Young is attributed to WNCC2 and is equal to $3.3 \mathrm{GPa}$. This confirms that these prepared nanoparticles display promising outlooks as nanocharges for reinforcing bio-based composites.

Moreover, the yield of CNC obtained in this study was still considerably great, with $21.6 \%-25.1 \%$ despite the great size reduction [24]. In terms of colloidal behavior, the analyzed zeta potential had negative values between $-10 \mathrm{mV}$ to $-16 \mathrm{mV}$, evidencing that the isolated CNCs particles could retain dispersed behavior under normal storage conditions [25,29]. It was possibly contributed by the formation of acetyl groups during hydrolysis that generated repulsion forces between CNC particles [14,24,31,32]. 
Besides this, Fig. 1 also illustrated the EDX spectra and Table 1 listed their composition details. From Table 1, carbon and oxygen atoms were the major components for each produced CNC sample [27]. The oxygen mass percentage was found lesser than carbon atoms in all samples, possibly due to the strong hydrogen bonding interaction between nanoparticles that had embedded some oxygen-containing hydroxyl groups [12,13]. This could be proven through the observed absorption peak in Fig. 1, where higher energy was needed to detect oxygen during the analysis process compared to carbon. However, the oxygen was increased from WNCC1 $(33.95 \%)$ to WNCC3 $(39.29 \%)$, signaling the hydrogen bonding was weakened throughout the acid hydrolysis and, ultimately singular nanoparticle was formed [30].

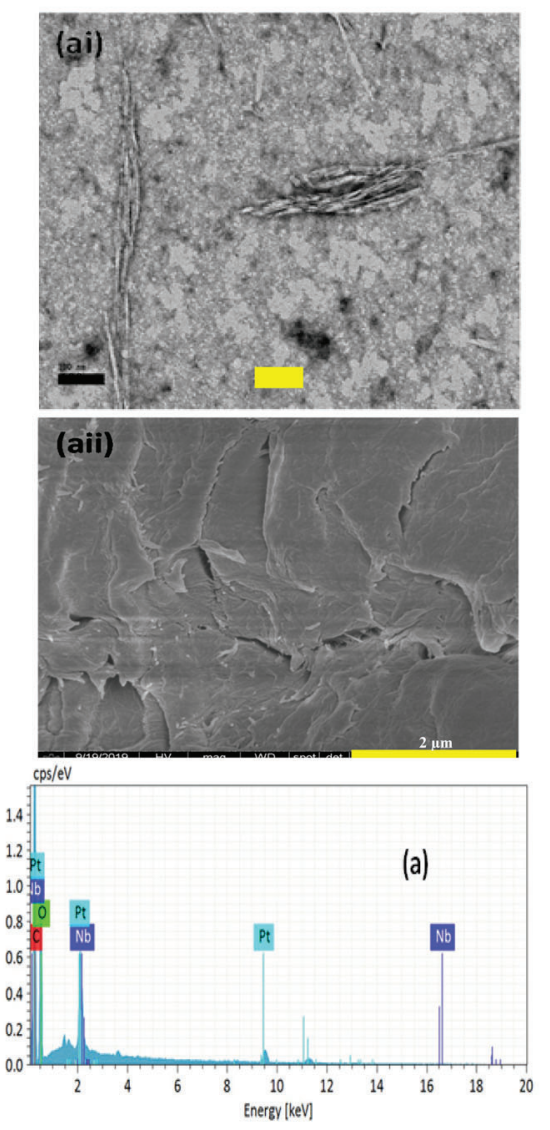

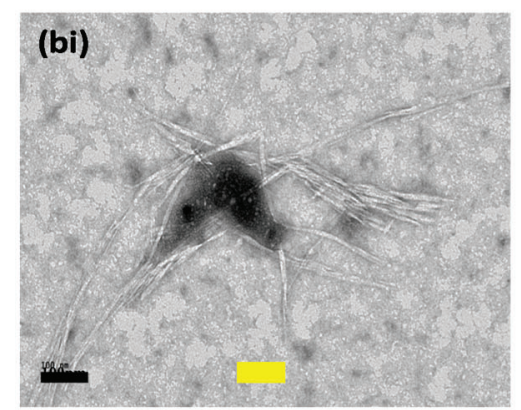
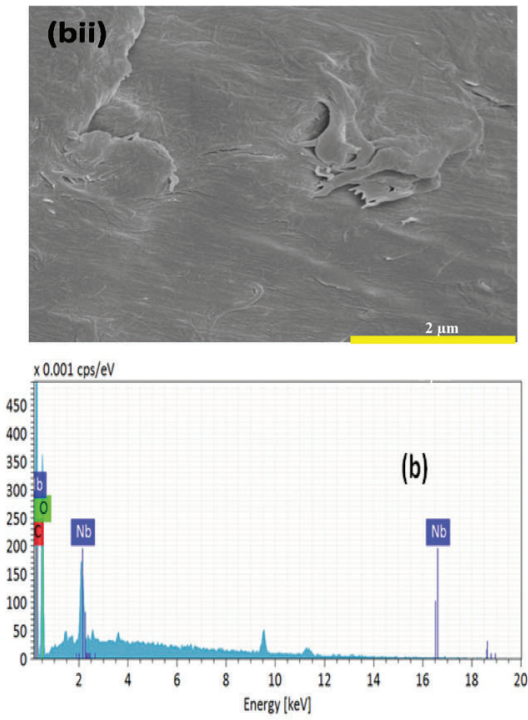
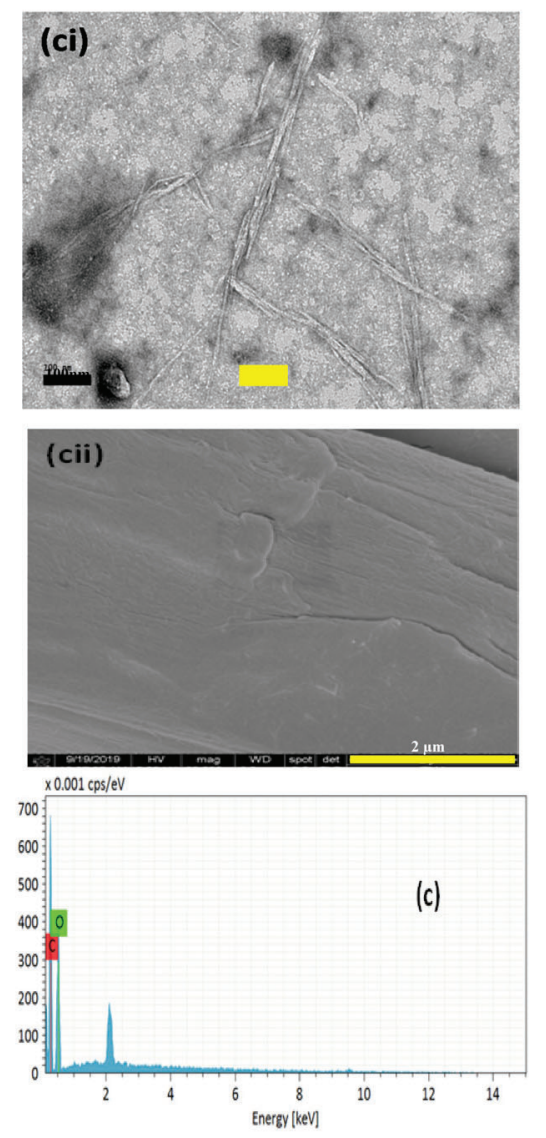

Figure 1: Energy Dispersive X-ray analysis, Transmission Electron Microscope (i) and FESEM (ii) micrographs of (a) WNCC1, (b) WNCC2, and (c) WNCC3

Table 1: Particle sizes, elements composition, zeta potential and yield of samples

\begin{tabular}{|c|c|c|c|c|c|c|c|c|}
\hline & $D(\mathrm{~nm})^{\mathrm{a}}$ & $L(\mathrm{~nm})^{\mathrm{b}}$ & $\mathrm{C}(\%)^{\mathrm{c}}$ & $O(\%)^{d}$ & $\mathrm{Nb}(\%)^{\mathrm{e}}$ & $\operatorname{Pt}(\%)^{f}$ & $\mathrm{Z}(\mathrm{mV})^{\mathbf{g}}$ & Yield (\%) \\
\hline WNCC1 & 11.27 & 247.60 & 64.66 & 33.95 & 0.77 & 0.62 & -11.9 & 25.1 \\
\hline WNCC2 & 8.68 & 260.49 & 62.42 & 37.05 & 0.52 & - & -13.8 & 22.3 \\
\hline WNCC3 & 8.55 & 193.84 & 60.71 & 39.29 & - & - & -15.4 & 21.6 \\
\hline
\end{tabular}

Note: ${ }^{a}$ Average of 100 measurements of width; ${ }^{\mathrm{b}}$ Average of 100 measurements length; ${ }^{\mathrm{c}}$ the amount of carbon; ${ }^{\mathrm{d}}$ the amount of oxygen; ${ }^{\mathrm{e}}$ Niobium; ${ }^{\mathrm{f}}$ Platinum and ${ }^{\mathrm{g}}$ Zeta Potential. 
Meanwhile, some impurities of niobium and platinum were mildly tracked for WNCC1 and WNCC2 samples, possibly due to their rougher surface morphology resulting in the uneven metal coating during specimen preparation [21]. Nonetheless, the pure cellulose compartment in WNCC3 with less impurity might endow it with non-toxic properties for certain application fields [28].

\subsection{The Infrared Spectroscopy}

Fig. 2 displayed that the infrared spectroscopy spectrum of prepared $\mathrm{CNC}$ was closely similar, showing the chemical groups were not modified by varied $\mathrm{HCl}$ acid concentrations [23]. It can be noticed that the absorption peak at about $3421 \mathrm{~cm}^{-1}$, representing the $-\mathrm{OH}$ vibration function of cellulose, was observed for the WNCC1 sample. This peak was shifted to $3525 \mathrm{~cm}^{-1}$ for $\mathrm{WNCC} 2$, and $3536 \mathrm{~cm}^{-1}$ for WNCC3, representing the cellulose order had changed via the different hydrogen bonding interactions [27]. Meanwhile, another peak at around $2969 \mathrm{~cm}^{-1}$ for WNCC1 also moved to $2924 \mathrm{~cm}^{-1}$ for WNCC2 and $2927 \mathrm{~cm}^{-1}$ for WNCC3. This peak was assigned to C-H bending, and it revealed that the exposure of cellulose was improved with the increased acid concentration [21].

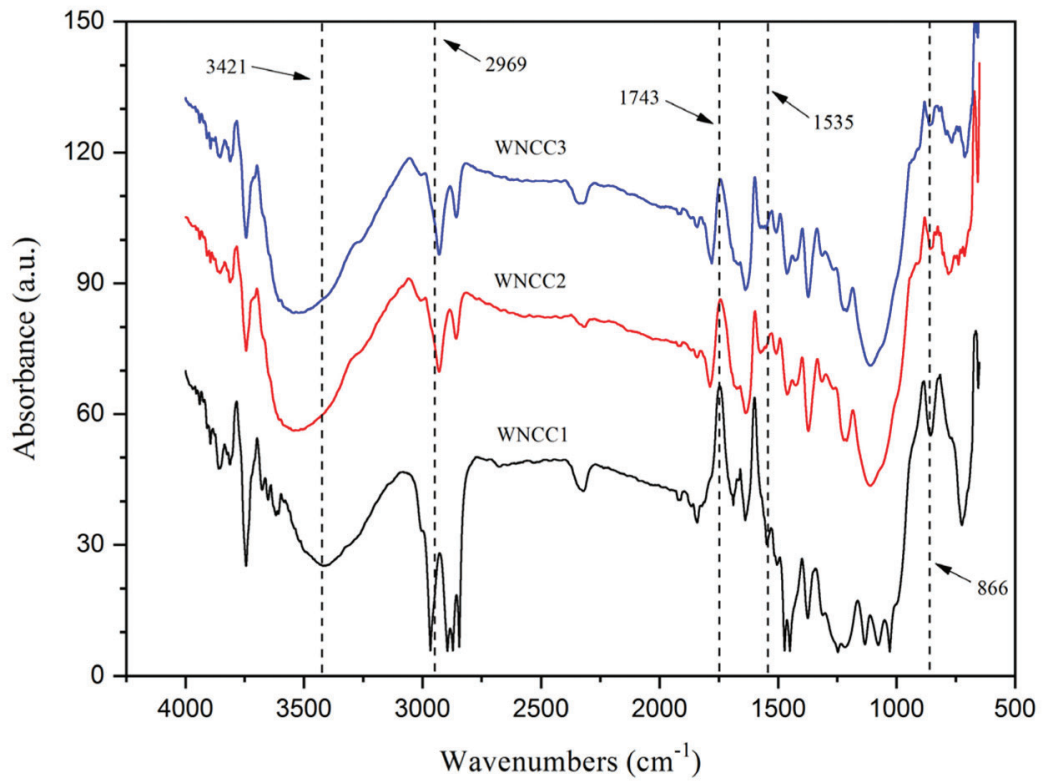

Figure 2: FTIR spectra of CNC samples

Besides this, the cellulose-water interaction bands at $1637 \mathrm{~cm}^{-1}$ and $1690 \mathrm{~cm}^{-1}$ were significantly observed for $\mathrm{WNCC} 1$. For both $\mathrm{WNCC} 2$ and $\mathrm{WNCC} 3$, these peaks were noted joining up as an overlapped peak rather than as two separated peaks. This evidenced the cellulose organization of WNCC2 and WNCC3 is more uniform in absorbing water when compared to WNCC1 [25,29]. The residual component, like hemicellulose, was substantially removed from all samples without a $1743 \mathrm{~cm}^{-1}$ peak associated with ester group stretching. Moreover, an additional small band at $1535 \mathrm{~cm}^{-1}$, corresponding to $\mathrm{C}=\mathrm{C}$ aromatic vibration in lignin, was noticed for $\mathrm{WNCC}$. This peak had disappeared in $\mathrm{WNCC} 2$ and $\mathrm{WNCC} 3$ samples, proving that the concentrated acid played a role in degrading lignin substance [12]. Furthermore, the 'crystallinity peaks' at $1424 \mathrm{~cm}^{-1}$ (symmetric $\mathrm{CH}_{2}$ stretching) and $1463 \mathrm{~cm}^{-1}$ (asymmetric $\mathrm{CH}_{2}$ stretching) had changed in intensities from WNCC1 to WNCC3, revealing the arrangement of crystallites cellulose was influenced with acid concentrations [22,24]. Additionally, the anhydroglucose-related peaks at $1375 \mathrm{~cm}^{-1}$ (C-H asymmetric stretching), $1090 \mathrm{~cm}^{-1}$ (C-O-C pyranose ring) and $866 \mathrm{~cm}^{-1}(\beta-1,4$-glycosidic linkage) were observed for each sample, signaling the typical chemical functionality of CNC product [34]. 


\subsection{XRD}

XRD diffractogram of CNCs is shown in Fig. 3. Each sample showed pronounced peaks at $15.1^{\circ}, 16.8^{\circ}$, $22.4^{\circ}$, and $34.6^{\circ}$, which correlating to respective $1-10,110,200$, and 004 crystallography planes of I $\beta$ cellulose polymorph building [24,34-37]. The peak intensity at $22.4^{\circ}$ was greatly enhanced for WNCC3, indicating the cellulose crystalline regions were predominant in the sample [22,29,31,32]. Meanwhile, the observed peaks at $15.1^{\circ}$ and $16.8^{\circ}$ were gradually changing in intensities from WNCC1 to WNCC3. It was probably due to the different acid concentrations that somehow affected the cellulose crystal organization $[6,30]$.

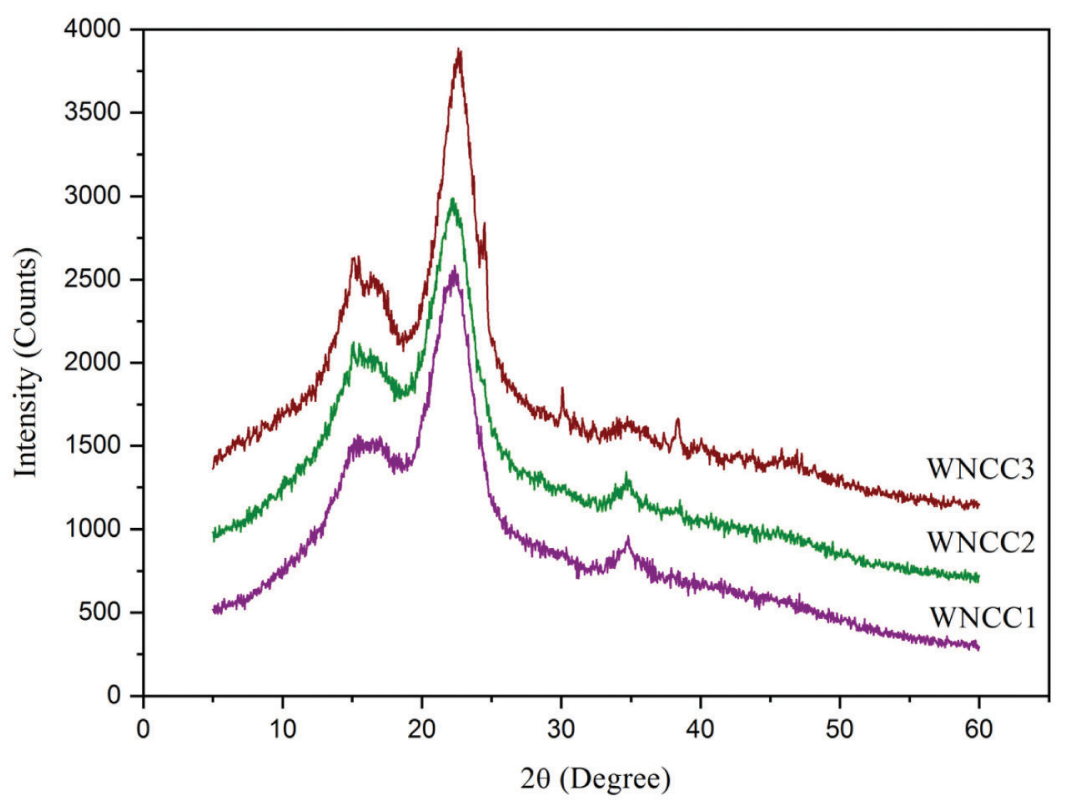

Figure 3: XRD spectra of nanoparticle samples

In addition, another small crystalline peak at about $34.6^{\circ}$ was noted for both $\mathrm{WNCC} 1$ and WNCC2, but this became obscure for the WNCC3 sample. This might be the non-uniform crystalline arrangement presented in WNCC3, caused by its severe acid hydrolysis condition [23,27]. Moreover, the determined crystallinity degrees were the highest with $76.2 \%$ for $\mathrm{WNCC} 3$, then followed by $74.9 \%$ for WNCC2\% and $72.3 \%$ for WNCC1. Finally, it can be noticed that an increase in the background noise is due to Compton's inconsistent scattering: waves scattered by different electrons do not interfere. This diffusion, therefore, does not cause diffraction but an increase in the background noise. Moreover, this figure can observe some residual peaks (between $30^{\circ}$ and $50^{\circ}$ ). Such phenomena can be corresponding to the presents of some salt's compounds leading from the hydrolysis step and especially from the HCL solution, which is not with higher purity [9-10,32].

\subsection{Thermal Analysis}

Thermal analysis is studied through the TGA curves presented in Fig. 4, and the result is recapitulated in Table 2.

As expected, each analyzed sample showed a typical behavior that corresponds to the weight loss in the temperature profile of $70-120^{\circ} \mathrm{C}$ and as a result of the volatized water content [22]. In the second stage of weight loss beyond $200^{\circ} \mathrm{C}$, both $\mathrm{WNCC} 2$ and $\mathrm{WNCC} 3$ revealed remarkably higher degradation temperature than $\mathrm{WNCC} 1$, implying the great thermal resistant nano-crystallite structures could be 
extracted with concentrated acid [27]. However, the sample of WNCC3 possessed a slightly lower degradation temperature comparing to WNCC2, which likely the concentrated acid for WNCC3 had influenced its cellulose crystal order arrangement as aforementioned.
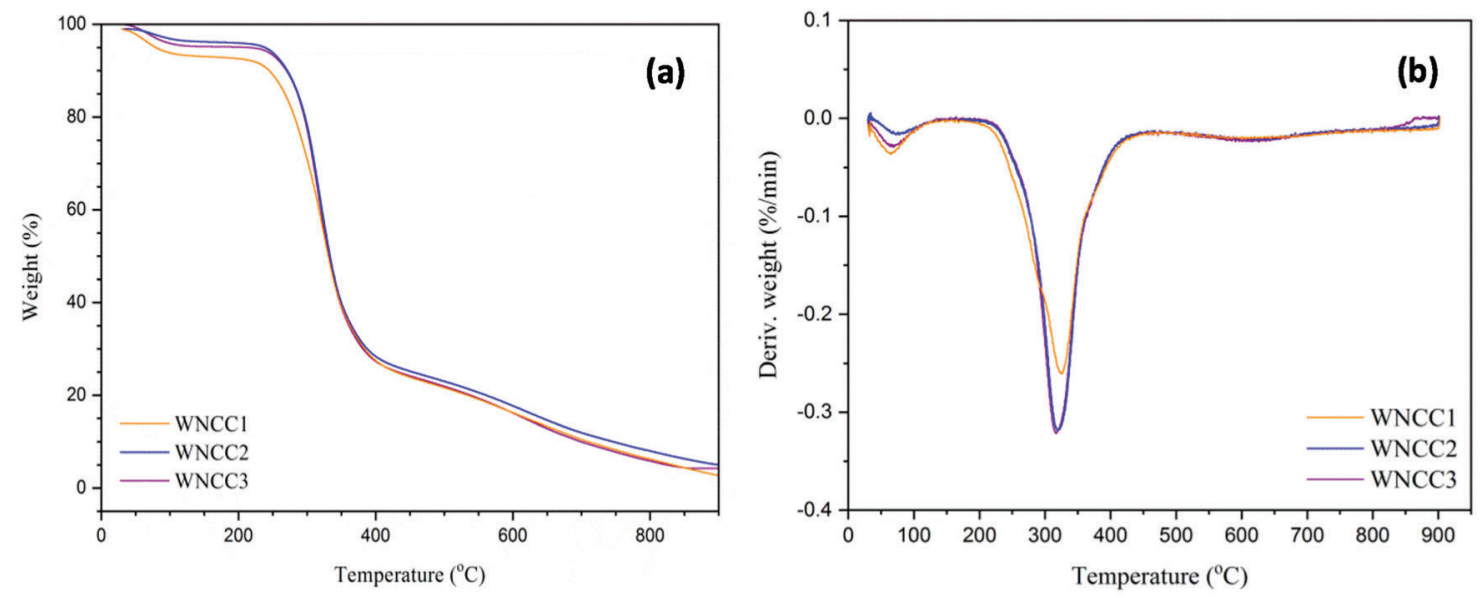

Figure 4: (a) Thermogravimetry and (b) Derivative thermogram (DTG) curves of nanoparticle samples

Table 2: Thermal analysis data of nanoparticle samples

\begin{tabular}{|c|c|c|c|c|}
\hline Samples & $\mathbf{O}_{\mathrm{dT}}\left({ }^{\circ} \mathrm{C}\right)^{\mathbf{a}}$ & $\mathbf{P}_{\mathrm{dT}}\left({ }^{\circ} \mathbf{C}\right)^{\mathrm{b}}$ & $M_{W L}(\%)^{c}$ & $\mathbf{R}_{W}(\%)^{d}$ \\
\hline WNCC1 & 257.5 & 324.3 & 90.8 & 4.4 \\
\hline WNCC2 & 280.8 & 319.9 & 91.2 & 4.9 \\
\hline WNCC3 & 278.0 & 317.5 & 91.5 & 5.7 \\
\hline
\end{tabular}

The degradation behavior had become more consistent for all $\mathrm{CNC}$ samples, and they formed symmetrical curves after $250^{\circ} \mathrm{C}$. This might prove that the produced native crystalline structure retains the same for each sample after hydrolysis [24]. Beyond $400^{\circ} \mathrm{C}$ temperature, WNCC2 showed the least weight loss among those samples, revealing its strong crystallite structure in resisting final thermal degradation [30]. From DTG curves, WNCC1 showed its peak degradation at a temperature of $324.3^{\circ} \mathrm{C}$, higher than that of WNCC2 and WNCC3 samples. The agglomerated nanostructure of WNCC1 might have improved its endurance towards the cellulose decomposition process [21].

WNCC2 and WNCC3 samples formed well-resolved curves with peaks degradation that closed to each other at about $318.0^{\circ} \mathrm{C}$ temperature, indicating their highly pure isolated cellulose crystal content [38]. The thermo-molecular behavior within CNC samples was analyzed with DSC spectra, as shown in Fig. 5. Heat energy was absorbed initially by each $\mathrm{CNC}$ sample for evaporating remained water content where the large endothermic bands were shown in the region of $60-140^{\circ} \mathrm{C}$ [17]. Subsequently, a series of endotherms and exotherms were observed at $140-200^{\circ} \mathrm{C}$ for all samples. This temperature range, relating to the cellulose decarboxylation, was slightly shifted to the right for WNCC2 and WNCC3 compared to the WNCC1 sample. It showcased that the cellulose crystallite was greatly exposed in WNCC2 and WNCC3, requiring higher heat energy for the decarboxylation mechanism [34]. 


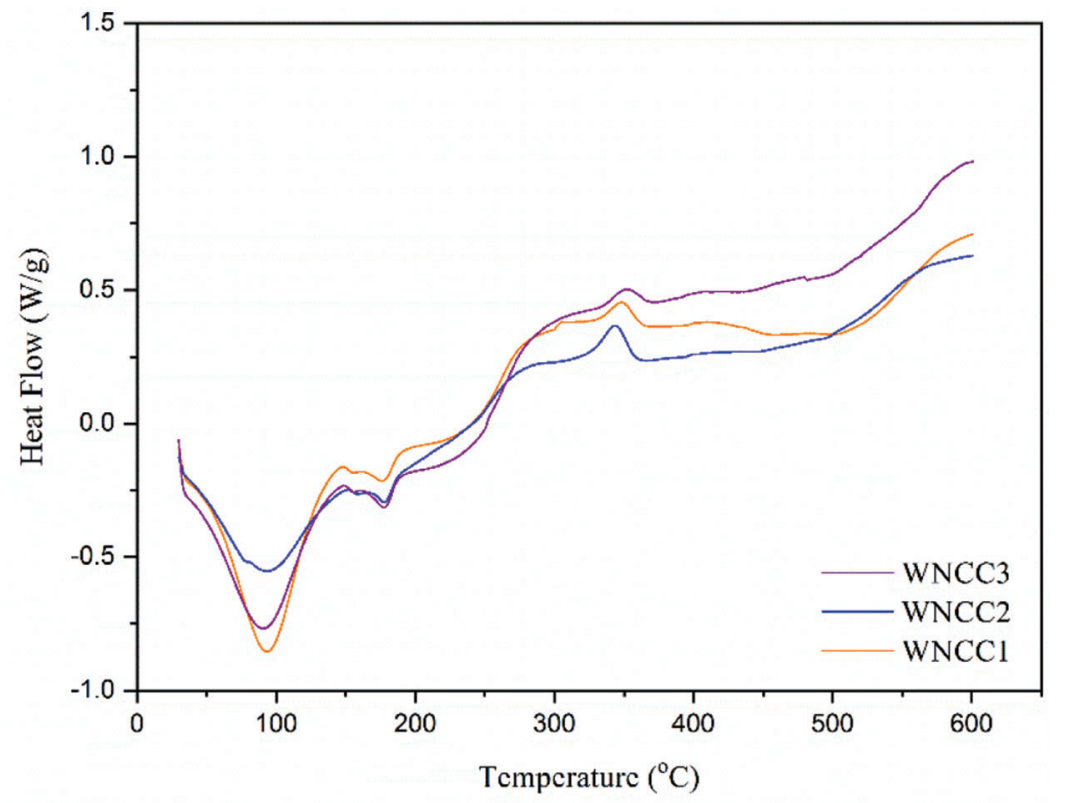

Figure 5: DSC spectra of nanoparticle samples

Later on, the main decomposition process was noticed happening from $250^{\circ} \mathrm{C}$ to $380^{\circ} \mathrm{C}$. In this region, a mildly right shifting exothermic peak was observed for $\mathrm{WNCC} 3$ at $353.1^{\circ} \mathrm{C}$ when comparing to $\mathrm{WNCC} 1$ at $346.7^{\circ} \mathrm{C}$ and $\mathrm{WNCC} 2$ at $346.2^{\circ} \mathrm{C}$. This proved that the thermal decomposition of cellulose was more stable in $\mathrm{WNCC} 3$ than other samples. Interestingly, an insignificant peak was noted at $306.8^{\circ} \mathrm{C}$ for the WNCC1 sample due to the inconsistent decomposition resulting from its aggregated feature [21]. Gasification and liquefaction processes of cellulose were lastly undergone by those samples beyond $400^{\circ} \mathrm{C}$. At this final stage, WNCC3 wisely released the heat energy for breaking down hydrocarbons bonding, indicating the produced cellulose compartment was pure for the sample $[39,40]$.

\section{Conclusion}

This paper was making the accent of utilizing different acid concentrations for isolating CNC products from Washingtonia fibre. From morphology examination, individually well-dispersed CNC particles with rod-like shapes were successfully obtained throughout the chemical treatments. The isolated CNC particles also contain pure cellulose elements composition and less impurity, giving it the potentiality employed in food, pharmaceutical and biomedical applications. Meanwhile, the crystalline structure of $\mathrm{CNC}$ particles was insignificantly affected by the increased acid concentrations. In addition, high thermal resistance property is also possessed by those CNC particles, endowing them with suitability applied in extreme temperature processing conditions. This paper describes numerous promising results: (i) a low concentrated $\mathrm{HCl}$ hydrolysis method used to prepare cellulose nanocrystals. (ii) Compared to the sulfuric acid hydrolysis approach, this process is extra environmentally friendly. (iii) Physiochemical and morphological properties are comparable to other CNCs. (iv) Excellent cellulose nanocrystals were prepared from Washingtonia Fibre which was justified by the obtained aspect ratios, and (v) the degree of crystallinity is determinate, equal to $75 \%$, and good thermal properties were also observed. Finally, the CNC from Washingtonia fibre could be hopeful alternative biomass for manufacturing CNC products in the future.

Funding Statement: This work is funded by Researchers Supporting Project number (RSP-2021/117), King Saud University, Riyadh, Saudi Arabia. The authors would like to thank the "PHC Utique" program of the 
French Ministry of Foreign Affairs and Ministry of Higher Education and Research, and the Tunisian Ministry of Higher Education and Scientific Research in the CMCU Project No. 18G1132 for the financial support.

Conflicts of Interest: The authors declare that they have no conflicts of interest to report regarding the present study.

\section{References}

1. Lizundia, E., Puglia, D., Nguyen, T. D., Armentano, I. (2020). Cellulose nanocrystal based multifunctional nanohybrids. Progress in Materials Science, 112, 100668. DOI 10.1016/j.pmatsci.2020.100668.

2. Verfaillie, A., Blockx, J., Praveenkumar, R., Thielemans, W., Muylaert, K. (2020). Harvesting of marine microalgae using cationic cellulose nanocrystals. Carbohydrate Polymers, 240, 116165. DOI 10.1016/j. carbpol.2020.116165.

3. Khiari, R., Mhenni, M. F., Belgacem, M. N., Mauret, E. (2010). Chemical composition and pulping of date palm rachis and posidonia oceanica-A comparison with other wood and non-wood fibre sources. Bioresources and Technology, 101, 775-780. DOI 10.1016/j.biortech.2009.08.07.

4. Fillat, U., Wicklein, B., Sampedro, R. M., Ibarra, D., Hitzky, E. R. et al. (2018). Assessing cellulose nanofiber production from olive tree pruning residue. Carbohydrate Polymers, 179, 252-261. DOI 10.1016/j.carbpol.2017.09.072.

5. Jiang, Q., Xing, X., Jing, Y., Han, Y. (2020). Preparation of cellulose nanocrystals based on waste paper via different systems. International Journal of Biological Macromolecules, 149, 1318-1322. DOI 10.1016/j. ijbiomac.2020.02.110.

6. Nomura, S., Kugo, Y., Erata, T. (2020). ${ }^{13} \mathrm{C}$ NMR and XRD studies on the enhancement of cellulose II crystallinity with low concentration NaOH post-treatments. Cellulose, 27, 3553-3563. DOI 10.1007/s10570-020-03036-6.

7. Cangelosi, B., Clematis, F., Monroy, F., Roversi, P. F., Troiano, R. et al. (2015). Filiferol, a chalconoid analogue from washingtonia filifera possibly involved in the defence against the Red palm weevil rhynchophorus ferrugineus olivier. Phytochemistry, 115(1), 216-221. DOI 10.1016/j.phytochem.2015.02.008.

8. Nehdi, I. A. (2011). Characteristics and composition of washingtonia filifera (Linden ex andré) H. Wendl. Seed and Seed oil. Food Chemistry, 126(1), 197-202. DOI 10.1016/j.foodchem.2010.10.099.

9. Khiari, R., Belgacem, M. N. (2017). 21-Potential for using multiscale posidonia oceanica waste: Current status and prospects in material science. In: Jawaid, M., Tahir Naheed Saba, P. M., Lignocellulosic fibre and biomass-Based composite materials, pp. 447-471. Woodhead Publishing Series in Composites Science and Engineering. Woodhead Publishing. DOI 10.1016/B978-0-08-100959-8.00021-4.

10. Khiari, R., Belgacem, M. N. (2020). Date palm nanofibres and composites. In: Midani M., Saba N., Alothman O. Y., Date palm fiber composites: Processing, properties and applications, pp. 185-206. Composites Science and Technology. Singapore: Springer. DOI 10.1007/978-981-15-9339-0_6.

11. Doh, H., Lee, M. H., Whiteside, W. S. (2020). Physicochemical characteristics of cellulose nanocrystals isolated from seaweed biomass. Food Hydrocolloids, 102(105542), 1-9. DOI 10.1016/j.foodhyd.2019.105542.

12. Khattab, T. A., Fouda, M. M. G., Rehan, M., Okla, M. K., Alamri, S. A. et al. (2020). Novel halochromic cellulose nanowhiskers from rice straw: Visual detection of urea. Carbohydrate Polymers, 231, 115740. DOI 10.1016/j. carbpol.2019.115740.

13. Kian, L. K., Saba, N., Jawaid, M., Alothman, O. Y., Fouad, H. (2020). Properties and characteristics of cellulose nanocrystal isolated from olive fiber. Carbohydrate Polymers, 241, 116423. DOI 10.1016/j.carbpol.2020.116423.

14. Su, F., Liu, D., Li, M., Li, Q., Liu, C. et al. (2020). Mesophase transition of cellulose nanocrystals aroused by the incorporation of two cellulose derivatives. Carbohydrate Polymers, 233, 115843. DOI 10.1016/j. carbpol.2020.115843.

15. Alharthi, S., Grishkewich, N., Berry, R. M., Tam, K. C. (2020). Functional cellulose nanocrystals containing cationic and thermo-responsive polymer brushes. Carbohydrate Polymers, 246, 1-9. DOI 10.1016/j. carbpol.2020.116651. 
16. Gao, A., Chen, H., Tang, J., Xie, K., Hou, A. (2020). Efficient extraction of cellulose nanocrystals from waste calotropis gigantea fiber by $\mathrm{SO}_{4}^{2-} / \mathrm{TiO}_{2}$ nano-solid superacid catalyst combined with ball milling exfoliation. Industrial Crops and Products, 152, 112524. DOI 10.1016/j.indcrop.2020.112524.

17. Pirich, C. L., Picheth, G. F., Machado, J. P. E., Sakakibara, C. N., Martin, A. A. et al. (2019). Influence of mechanical pretreatment to isolate cellulose nanocrystals by sulfuric acid hydrolysis. International Journal of Biological Macromolecules, 130, 622-626. DOI 10.1016/j.ijbiomac.2019.02.166.

18. Sutliff, B. P., Das, A., Youngblood, J., Bortner, M. J. (2020). High shear capillary rheometry of cellulose nanocrystals for industrially relevant processing. Carbohydrate Polymers, 231, 115735. DOI 10.1016/j. carbpol.2019.115735.

19. Khanjanzadeh, H., Behrooz, R., Bahramifar, N., Pinkl, S., Altmutter, W. G. (2019). Application of surface chemical functionalized cellulose nanocrystals to improve the performance of UF adhesives used in wood based composites-MDF type. Carbohydrate Polymers, 206, 11-20. DOI 10.1016/j.carbpol.2018.10.115.

20. Zhang, Q., Zhang, L., Wu, W., Xiao, H. (2020). Methods and applications of nanocellulose loaded with inorganic nanomaterials: A review. Carbohydrate Polymers, 229, 115454. DOI 10.1016/j.carbpol.2019.115454.

21. Xing, L., Gu, J., Zhang, W., Tu, D., Hu, C. (2018). Cellulose I and II nanocrystals produced by sulfuric acid hydrolysis of tetra pak cellulose I. Carbohydrate Polymers, 192, 184-192. DOI 10.1016/j.carbpol.2018.03.042.

22. Benini, K. C. C., Voorwald, H. J. C., Cioffi, M. O. H., Rezende, M. C., Arantes, V. (2018). Preparation of nanocellulose from imperata brasiliensis grass using taguchi method. Carbohydrate Polymers, 192, 337-346. DOI 10.1016/j.carbpol.2018.03.055.

23. Teodoro, K. B. R., Migliorini, F. L., Facure, M. H. M., Correa, D. S. (2019). Conductive electrospun nanofibers containing cellulose nanowhiskers and reduced graphene oxide for the electrochemical detection of mercury(II). Carbohydrate Polymers, 207, 747-754. DOI 10.1016/j.carbpol.2018.12.022.

24. Seta, F. T., An, X., Liu, L., Zhang, H., Yang, J. et al. (2020). Preparation and characterization of high yield cellulose nanocrystals (CNC) derived from ball mill pretreatment and maleic acid hydrolysis. Carbohydrate Polymers, 234, 115942. DOI 10.1016/j.carbpol.2020.115942.

25. Baek, J., Pedro, F. W., Kim, K., Kim, K., Tam, K. C. (2019). Phosphorylated-cNC/modified-chitosan nanocomplexes for the stabilization of pickering emulsions. Carbohydrate Polymers, 206, 520-527. DOI 10.1016/j.carbpol.2018.11.006.

26. Segal, L., Creely, J. J., Martin, A. E., Conrad, C. M. (1959). An empirical method for estimating the degree of crystallinity of native cellulose using the X-ray diffractometer. Textile Research Journal, 29(10), 786-94. DOI 10.1177/004051755902901003.

27. Du, W. B., Deng, A., Guo, J., Chen, J., Li, H. et al. (2019). An injectable self-healing hydrogel-cellulose nanocrystals conjugate with excellent mechanical strength and good biocompatibility. Carbohydrate Polymers, 223, 115084. DOI 10.1016/j.carbpol.2019.115084.

28. Omidi, S., Pirhayati, M., Kakanejadifard, A. (2020). Co-delivery of doxorubicin and curcumin by a pH-sensitive, injectable, and in situ hydrogel composed of chitosan, graphene, and cellulose nanowhisker. Carbohydrate Polymers, 231, 115745. DOI 10.1016/j.carbpol.2019.115745.

29. Lee, H., You, J., Jin, H. J., Kwak, H. W. (2020). Chemical and physical reinforcement behavior of dialdehyde nanocellulose in PVA composite film: A comparison of nanofiber and nanocrystal. Carbohydrate Polymers, 232, 115771. DOI 10.1016/j.carbpol.2019.115771.

30. Li, Y., Zhang, J., Zhan, C., Kong, F., Li, W. et al. (2020). Facile synthesis of $\mathrm{TiO}_{2} / \mathrm{CNC}$ nanocomposites for enhanced $\mathrm{Cr}(\mathrm{VI})$ photoreduction: Synergistic roles of cellulose nanocrystals. Carbohydrate Polymers, 233(115838), 1-11. DOI 10.1016/j.carbpol.2020.115838.

31. Bettaieb, F., Khiari, R., Dufresne, A., Mhenni, M. F., Belgacem, M. N. (2015). Mechanical and thermal properties of posidonia oceanica cellulose nanocrystal reinforced polymer. Carbohydrate Polymers, 123, 99-104. DOI 10.1016/j.carbpol.2015.01.026.

32. Bettaieb, F., Khiari, R., Hassan, M. L., Belgacem, M. N., Bras, J. et al. (2015). Preparation and characterization of new cellulose nanocrystals from marine biomass posidonia oceanica. Industrial Crops and Products, 72, 175-182. DOI 10.1016/j.indcrop.2014.12.038. 
33. Bras, J., Viet, D., Bruzzese, C., Dufresne, A. (2011). Correlation between stiffness of sheets prepared from cellulose whiskers andnanoparticles dimensions. Carbohydrate Polymers, 84, 211-215. DOI 10.1016/j. carbpol.2010.11.022.

34. Chargot, M. S., Chylińska, M., Pieczywek, P. M., Zdunek, A. (2019). Tailored nanocellulose structure depending on the origin. example of apple parenchyma and carrot root celluloses. Carbohydrate Polymers, 210, 186-195. DOI 10.1016/j.carbpol.2019.01.070.

35. Chen, H., Sharma, S. K., Sharma, P. R., Yeh, H., Johnson, K. et al. (2019). Arsenic (III) removal by nanostructured dialdehyde cellulose-Cysteine microscale and nanoscale fibers. ACS Omega, 4(26), 22008-22020. DOI 10.1021/ acsomega.9b03078.

36. Sharma, P. R., Sharma, S. K., Lindström, T., Hsiao, B. S. (2020). Nanocellulose-enabled membranes for water purification: Perspectives. Advanced Sustainable Systems, 4, 1-28. DOI 10.1002/adsu.201900114.

37. Zhan, C., Sharma, P. R., He, H., Sharma, S. K., McCauley-Pearl, A. et al. (2020). Rice husk based nanocellulose scaffolds for highly efficient removal of heavy metal ions from contaminated water. Environmental Science: Water Research \& Technology, 6(11), 3080-3090. DOI 10.1039/D0EW00545B.

38. Vasconcelos, N. F., Feitosa, J. P. A., Gama, F. M. P., Morais, J. P. S., Andrade, F. K. et al. (2017). Bacterial cellulose nanocrystals produced under different hydrolysis conditions: Properties and morphological features. Carbohydrate Polymers, 155, 425-431. DOI 10.1016/j.carbpol.2016.08.090.

39. Bano, S., Negi, Y. S. (2017). Studies on cellulose nanocrystals isolated from groundnut shells. Carbohydrate Polymers, 157, 1041-1049. DOI 10.1016/j.carbpol.2016.10.069.

40. Taflick, T., Schwendler, L. A., Rosa, S. M. L., Bica, C. I. D., Nachtigall, S. M. B. (2017). Cellulose nanocrystals from acacia bark-Influence of solvent extraction. International Journal of Biological Macromolecules, 101, 553-561. DOI 10.1016/j.jibiomac.2017.03.076. 